\title{
Research in exercise physiology and dyspnea at McMaster University
}

\author{
Norman L Jones MD FRCP FRCPC
}

$\mathrm{D}_{\mathrm{s}}^{\mathrm{s}}$ EJ Moran Campbell arrived in Hamilton, Ontario, in September 1968, as the founding chairman of the Department of Medicine at McMaster University Medical Centre (Hamilton, Ontario). He had asked me to be the Head of the Regional Respiratory Program, and I followed him two weeks later. We had worked together at the Royal Postgraduate Medical School, Hammersmith Hospital, for several years to develop a system of exercise testing that could be routinely applied to any clinical problem associated with effort intolerance. We also each had our own separate obsessions; Moran's obsession was in dyspnea, and mine was in exercise metabolism. The three research streams - exercise testing, metabolism and dyspnea - gradually gained momentum, largely due to the hard work of graduate students and fellows. In the present brief overview, I hope to acknowledge their contribution as much as the progress we made in these topics.

\section{CARBON DIOXIDE-BASED SYSTEM OF EXERCISE TESTING}

Many years ago, Sir Joseph Barcroft observed that exercise requires the coordinated interaction between several physiological systems; in his words, "every adaptation is an integration" (1). Muscle metabolism, cardiac output, circulation, ventilation, pulmonary gas exchange and the patient's perception of these events are all needed in clinical assessment.

In contrast to the delivery of $\mathrm{O}_{2}$, we focused on $\mathrm{CO}_{2}$ removal. The integration of mechanisms involved in $\mathrm{CO}_{2}$ output was similar to $\mathrm{O}_{2}$ intake, but the measurements were simpler. The removal of $\mathrm{CO}_{2}$ was just as important as $\mathrm{O}_{2}$ delivery. Furthermore, $\mathrm{CO}_{2}$ output reflected both aerobic metabolism and lactate production, both influencing acid-base homeostasis. Finally, $\mathrm{CO}_{2}$ was easier to measure, and cardiac output could be measured noninvasively using a $\mathrm{CO}_{2}$ rebreathing method.

In Hamilton, this became the starting point for new research endeavours, based at St Joseph's Hospital, where the Regional Respiratory Centre was established. Denis Robertson, an Australian research fellow who had started with us at the Hammersmith Hospital, came to Hamilton on a Medical Research Council of Canada fellowship. Jim Kane joined us from Winnipeg, Manitoba, as chief technologist, and Ann Hart took a leave of absence from Hammersmith Hospital to become our senior research technologist. Monte Smith brought his skills as a systems analyst in the early days of computers in clinical physiology. The key measurement was the (rebreathing) oxygenated mixed venous partial pressure of $\mathrm{CO}_{2}\left(\mathrm{P} \overline{\mathrm{v}} \mathrm{CO}_{2}\right)$. Two methods existed: the equilibration method, ie, the rebreathing of a high $\mathrm{CO}_{2}$ gas mixture to obtain an equilibrium between gas and blood; and the Defares method, ie, the rebreathing of a low $\mathrm{CO}_{2}$ mixture in which the $\mathrm{CO}_{2}$ concentration rose asymptotically toward an equilibrium, which was calculated rather than measured. The equilibrium method was favoured because it was unaffected by ventilationperfusion problems; poorly ventilated areas in the lungs have gas tensions close to mixed venous values. However, the equilibrium gaseous $\mathrm{P}_{\bar{v}} \mathrm{CO}_{2}$ was higher than the value in arterial blood sampled at the same time. The 'downstream $\mathrm{P}_{\bar{v}} \mathrm{CO}_{2}$ difference' increased with increasing power (2), requiring a correction to be applied to derive the 'true' mixed venous $\mathrm{P}_{\bar{v}} \mathrm{CO}_{2}$. Alves da Silva et al (3) showed that the Defares method yielded an estimated mixed venous $\mathrm{P}_{\nabla} \mathrm{CO}_{2}$ that did not require this correction. Meanwhile, a systematic examination of factors influencing the difference between end-tidal and arterial $\mathrm{P}_{\bar{v}} \mathrm{CO}_{2}$ provided a useful method for estimating arterial $\mathrm{P}_{\bar{v}} \mathrm{CO}_{2}$ during exercise (4).

Measurements of cardiac output in exercise have always been believed to require a 'steady state' in metabolic and cardiovascular variables. McKelvie et al (5) found that measurements in short-term incremental exercise were comparable with steady-state results. Steady-state exercise was replaced by an incremental test in which power was increased by $100 \mathrm{kpm} / \mathrm{min}(16 \mathrm{~W})$ at $1 \mathrm{~min}$ intervals. This allowed most subjects to reach maximum tolerated power in less than $20 \mathrm{~min}$, with the exception of highly trained athletes.

Lydia Makrides, a career physiotherapist working toward her $\mathrm{PhD}$, organized a carefully designed study in 100 subjects (50 male and 50 female) to establish normal standards for maximum power, heart rate and ventilation (6). These were expressed as linear additive functions of height and weight. The shortcomings of this approach became apparent as our experience evolved. Tony Sargeant spent a sabbatical year in the department and introduced us to muscle performance measured with an isokinetic ergometer. The ergometer was constructed (7), and Neil McCartney and colleagues used the method in a number of experiments to study muscle strength and fatigue characteristics at different pedalling frequencies (8-10). Close relationships were found between muscle strength and maximum $\mathrm{O}_{2}$ uptake (11). In another study by Makrides et al (12), six weeks of high-intensity resistance training in 60- to 70-year-old men improved maximal $\mathrm{O}_{2}$ uptake by $40 \%$. Simpson et al (13) conducted a similar study in chronic obstructive pulmonary disease (COPD) patients, demonstrating similar improvements (13).

Department of Medicine, Michael G DeGroote School of Medicine, McMaster University, Hamilton, Ontario

Correspondence: Dr Norman L Jones, Cardiorespiratory Unit, 3U1 McMaster University Medical Centre, 1200 Main Street West, Hamilton, Ontario L8S 325. E-mail jonesn@mcmaster.ca 
The clinical exercise laboratory functioned in parallel to these projects. Measurements of muscle strength, ventilatory capacity (from maximal inspiratory and expiratory flow or volume characteristics), gas transfer capacity and arterialized capillary blood sampling were systematically gathered in all patients with cardiovascular, respiratory and other disorders undergoing exercise testing. Psychophysical rating of symptoms, coupled with resting and exercise data, allowed us to see symptoms in a new light.

George Obminski designed a computerized system for storing all our clinical data. A very large database has accumulated, comprising all patients referred for exercise testing, including diagnosis and current medications, anthropometric data, isokinetic muscle strength and pulmonary function (spirometry, carbon monoxide uptake, respiratory muscle strength) measurements. Now, there is a database comprising 40,000 records, which has allowed Kieran Killian to study the impact of pulmonary function impairment and muscle weakness on exercise capacity. Symptoms play a fundamental role in limiting exercise; when symptoms become intolerable, further exercise ceases. During this research, Moran Campbell's goal of understanding dyspnea has been largely achieved. The distinction among dyspnea, perception of respiratory muscle effort, and breathlessness (the unpleasant urge to breathe that arises with respiratory failure) has been unravelled. Former confusion regarding these sensations has been resolved by applying psychophysical techniques that allow sensory intensity to be related to physiological measures of adaptation and integration to the demands of exercise.

Progressive incremental exercise to a symptom-limited maximum capacity, which we called the stage 1 test, has remained unchanged for at least the past 25 years, providing a standardized protocol to assess all disorders directly or indirectly related to respiration. The large numbers have allowed normal standards to be re-evaluated using more logical scaling principles. Both maximum capacity and maximal $\mathrm{O}_{2}$ uptake were shown to be proportionally lower in women than men; maximum capacity and maximal $\mathrm{O}_{2}$ uptake increase as a power function of height, and decline proportionally with age (14). With increased precision has come an increase in the ability to quantify disability and the underlying causes.

Although the stage 1 test remains the mainstay of our approach to clinical exercise testing, the $\mathrm{CO}_{2}$-based method without (stage 2) or with (stage 3) arterial blood gas sampling is useful in situations in which measurements of cardiac output and pulmonary gas exchange variables are needed (15). Finally, an additional method to follow progress in chronic heart and lung conditions was developed and validated by Guyatt et al (16) - the 6 min walk test.

\section{LACTATE PRODUCTION, MUSCLE METABOLISM AND ACID-BASE HOMEOSTASIS}

With Lavoisier, the idea emerged that the source of energy for exercise comes from chemical combustion (oxidation) of substances in the body. It was not until the early 20th century that the metabolic pathways of glycogen and fat oxidation were understood, together with their linkage to ATP production and the essential role of enzymes. Lactate production by muscle occurred in the absence of $\mathrm{O}_{2}$, leading to the concept of $\mathrm{O}_{2}$ debt, occurring when $\mathrm{O}_{2}$ demands by muscle exceeded its supply. Entering blood, lactic acid was buffered by bicarbonate, with an associated increase in $\mathrm{CO}_{2}$ evolution, expressed in the reaction:

$$
\mathrm{LaH}+\mathrm{HCO}_{3}^{-} \rightarrow \mathrm{La}^{-}+\mathrm{CO}_{2}+\mathrm{H}_{2} \mathrm{O}
$$

The two notions were combined in the concept of an 'anaerobic threshold', in which, during incremental exercise, a point was reached when $\mathrm{O}_{2}$ demands were unable to be met by the circulation; thus, lactate was produced and $\mathrm{CO}_{2}$ output increased out of proportion to $\mathrm{O}_{2}$ intake.

We were interested in the relationships among glycolysis, lactate production and fat use during exercise, approaching these topics in terms of enzyme regulation of the metabolic processes involved in ATP production. The importance of acid-base homeostasis soon became apparent.

\section{Lactate production}

A number of observations during the 1960s, as well as before this period, had suggested that a lack of $\mathrm{O}_{2}$ supply to muscle (' $\mathrm{O}_{2}$ debt') was not the only factor influencing lactate production by muscle. In 1969, Harris (17) wrote a paper with the provocative title "Lactic acid and the phlogiston debt", in which he suggested that the notion of $\mathrm{O}_{2}$ debt should suffer the same fate as Stahl's 17th century theory of combustion. Robert Taylor, an MSc student, wanted to understand why high intensity exercise appeared to be less fatiguing following sodium bicarbonate administration. His study showed that endurance was improved following bicarbonate (alkalosis) and reduced following ammonium chloride (acidosis) administration; interestingly, alkalosis was accompanied by higher blood lactate concentrations than either acidosis or control conditions (18). The acid-base state had clearly influenced lactate production in the absence of any effect on $\mathrm{O}_{2}$ delivery. In the early 1980 s, Spriet et al $(19,20)$ confirmed the metabolic and functional effects of acidosis and alkalosis in the isolated perfused rat hind limb, and McCartney et al (21) similarly demonstrated the effects in short-term (30 s) maximal isokinetic exercise (21).

A large increase in lactate production occurs during exercise at high altitudes and under hypoxic conditions at sea level. In 1972, we found that hypoxia was associated with both lactate production and free fatty acid mobilization (22); in contrast, acidosis was associated with reduced free fatty acid mobilization (18). In 1973, John Sutton joined the group on a one-year research fellowship. He stayed for 17 years. He brought a passionate interest in high-altitude physiology, which culminated in Operation Everest II (23). In his first study, needle muscle biopsies, using the technique pioneered by Eric Hultman in the 1960s, were performed to examine muscle metabolite changes during exercise in imposed alkalosis and acidosis. The same effects previously found in plasma were found in muscle; however, there was evidence of glycolytic enzyme inhibition in acidosis (24). Acidosis also impaired lactate efflux from muscle, an effect we now know is due to acidosis on the monocarboxylate transporter (25).

Eric Newsholme and Carole Start's seminal work Regulation in Metabolism (26) opened a new era by identifying the importance of rate-limiting enzymes. Enzyme binding characteristics are affected by changes in $\mathrm{pH}$; hence, there are clear links between acid-base homeostasis and the fuels used in exercise. The most complex of the enzymes regulating glycolysis is the pyruvate dehydrogenase complex (PDHc). PDHc regulates the entry of pyruvate into the citric acid (Krebs) cycle. If glycolysis increases to a greater extent than the activation of PDHc, pyruvate accumulates and lactate is 
formed. The flux-generating step in glycolysis, phosphorylase, is inhibited and $\mathrm{PDHc}$ activity stimulated by falls in $\mathrm{pH}$. These facts provide a plausible theory linking acid-base changes to lactate production. PDHc was known to be an important regulator of fat versus glycogen metabolism in normal and diabetic rat muscle, but its role in human muscle during exercise had not been studied. The difficult microbiochemical assays were developed in collaboration with Neil Toews. A succession of graduate students undertook both the organization of the studies and the analytical techniques. An initial series of experiments by Ward et al $(27,28)$ showed that the activation of PDHc occurred during exercise (27), and that $\mathrm{PDHc}$ concentration was increased by training and reduced following limb immobilization (28). Putnam et al $(29,30)$ extensively improved the analysis of PDHc, together with the activating phosphatase and inhibiting kinase, to study its control. He showed progressive activation with increasing exercise intensity (29) and duration of exercise, and also after a low-carbohydrate diet (30). A short training regime increased the rate at which PDHc was activated at the onset of exercise, explaining the associated reduction in lactate production (31).

Hollidge-Horvat et al (32) revisited the effects of imposed acidosis and alkalosis on metabolic control. They found that acidosis reduced lactate production through a combination of inhibitions of glycolytic enzymes and activation of PDHc; alkalosis increased lactate mainly through the activation of phosphorylase. Parolin et al (33) similarly established the importance of enzyme regulation in the response to hypoxia and exercise, with the activation of phosphorylase and the inhibition of PDHc. The respiratory alkalosis that accompanies hypoxemia is an important factor in this response. Administration of dichloroacetate, an activator of PDHc, lowered lactate without affecting phosphorylase activity (34).

These studies of metabolic control in exercise continue to this day under the direction of Spriet and Heigenhauser (35). The intramuscular concentrations of lactate, creatine phosphate, the products of ATP hydrolysis (ADP, AMP), and the activation of phosphorylase and PDHc form a highly coordinated system that ensures ATP regeneration through the most energetically economical pathways under the constraints imposed by substrate supply. The process of 'training' increases $\mathrm{PDHc}$ activation, together with regulators of glucose and fatty acid supply to the muscle. The changes are independent of $\mathrm{O}_{2}$ supply, making changes in $\mathrm{O}_{2}$ use the effect, rather than a cause, of the metabolic changes that accompany exercise. Reductions in $\mathrm{O}_{2}$ delivery to muscle are associated with lactate accumulation, but it is no longer acceptable to infer inadequate $\mathrm{O}_{2}$ delivery whenever increases in lactate occur.

\section{Acid-base homeostasis in exercise}

From the mid-1930s onwards, lactic acid accumulation was simply ascribed to an imbalance in $\mathrm{O}_{2}$ demand versus supply. Increases in lactate concentration were associated with reductions in bicarbonate and increases in $\mathrm{CO}_{2}$ output. When $\mathrm{CO}_{2}$ output and ventilation broke away from their link to $\mathrm{O}_{2}$ intake, an 'anaerobic threshold' was reached. The reductions in blood lactate, $\mathrm{CO}_{2}$ output and ventilation that accompanied training were consistent with this concept (36), but the links between these variables were never impressive. Uncertain 'buffering' made it impossible to quantify the independent factors that determined $\mathrm{pH}$, as well as bicarbonate, in blood and muscle during exercise. The results of studies in which acid-base homeostasis was manipulated did not conform to this simple concept.

In an effort to understand the inter-relationships, Spriet et al (37) developed an isolated perfused rat hind limb preparation. The model allowed the manipulation of the perfusate and the effects on muscle contraction, intramuscular metabolites and ionic changes across the limb to be observed. The muscle generated a maximum tension of $2500 \mathrm{~g}$ and behaved physiologically; the effects of acidosis (38) and alkalosis (19) on lactate release from the muscle were similar to those in human studies. However, there were differences between the effects of respiratory versus metabolic acid-base changes. Increments in lactate were not accompanied by equivalent falls in bicarbonate. Lactate accumulation was not the only factor influencing muscle $\mathrm{pH}$, and other ionic changes were just as important. Wendell Stainsby, of the University of Florida (USA), had also found that lactate increases were not accompanied by increases in hydrogen ion release. He suggested that we should consider the 'Stewart approach'. This became the turning point in our perception of acid-base control.

In 1983, Peter Stewart published "Modern quantitative acid-base chemistry" (39) in the Canadian Journal of Physiology and Pharmacology. The paper was accompanied by an enthusiastic editorial by Don Jennings of Queen's University (Kingston, Ontario). Stewart presented a new approach that was rigorously based on classical physicochemical principles. He identified the independent variables as strong (fully dissociated) ions, acting through the 'strong ion difference' (SID), the total concentration of weak acids (buffers) and the $\mathrm{CO}_{2}$ pressure. The equilibrium conditions among all the systems and the dependent variables, which included bicarbonate and $\mathrm{pH}$, were computed by solving a fourth-order polynomial expression. We were fortunate to have Peter Stewart, who had recently retired from Brown University (Rhode Island, USA), visit us and explain the approach. John Kowalchuk and Michael Lindinger enthusiastically adopted the approach in their studies to clarify the mechanisms contributing to the electrolyte changes in heavy exercise. Maximum exercise was chosen because of its associated large lactate and $\mathrm{CO}_{2}$ production. Previous work by McCartney et al (21) on the effects of acid-base changes during short-term (30 s) maximum isokinetic exercise suggested that this might be an appropriate model for the initial studies. The Stewart approach worked well when applied to plasma variables; calculated plasma $\mathrm{pH}$ agreed closely with measured $\mathrm{pH}$. Lindinger and Heigenhauser (40) applied neutron activation analysis to the measurement of intramuscular strong ions (mainly lactate, $\mathrm{K}^{+}$, $\mathrm{Na}^{+}$and $\mathrm{Cl}^{-}$); ionic exchange was assessed by arterial and venous sampling across the leg. The study cast new light on the processes of ionic control and intramuscular $\mathrm{pH}$ regulation. Kowalchuck et al (41) found that lactic acid production did not account for falls in intramuscular $\mathrm{pH}$. Increases in lactate concentration, tending to reduce [SID], were offset by reductions in creatine phosphate concentration; the effect of both exercise intensity and duration on changes in lactate were remarkably similar, although in an opposite direction to creatine phosphate. Early in exercise, a large increase in $\mathrm{P}_{\bar{\nabla}} \mathrm{CO}_{2}$, which could exceed $100 \mathrm{mmHg}$ in muscle during heavy work, facilitated rapid efflux of $\mathrm{CO}_{2}$ from muscle, contributing to falls in intramuscular bicarbonate concentration and an apparent movement of bicarbonate from muscle into 
venous plasma; however, half of the increase in bicarbonate was accounted for by the movement of $\mathrm{Cl}^{-}$out of plasma (41). In a second study, Kowalchuck et al (42) measured the changes in blood flowing through inactive forearm muscle after intense leg exercise. The lactate left the plasma, accounting for almost half the $10 \mathrm{mmol} / \mathrm{L}$ increase in plasma bicarbonate, with $\mathrm{Cl}^{-}$accounting for the remainder.

The role played by red blood cells in homeostasis was studied by Robert McKelvie. The Stewart approach was applied to red blood cells; blood samples were hemolyzed and ion concentrations were measured. Red blood cell concentrations were derived from the hematocrit and plasma ion concentrations. The initial studies showed that lactate concentrations in red blood cells never reached plasma levels, and the main factor protecting plasma bicarbonate was an influx of chloride into red blood cells (Hamburger shift) (43). Changes in bicarbonate in muscle, plasma and red blood cells were dominated by $\mathrm{P}_{\bar{v}} \mathrm{CO}_{2}$ and [SID].

Training has long been known to reduce the increases in plasma hydrogen ion concentration that accompany heavy exercise. Putman et al (44) showed that this effect is only partly due to less lactate production by muscle; there is also less water uptake by muscle, as well as less uptake of lactate and $\mathrm{Cl}^{-}$ by red blood cells, contributing to greater [SID] and a reduction in plasma weak acid concentration. McKenna et al (45) examined a sprint training regime to show similar ionic changes. Among other benefits, sprint training ameliorated the ionic changes associated with heavy exercise.

Oded Bar-Or joined the Department of Pediatrics at McMaster University Medical Centre in the late 1970s and established a children's exercise program. He did extensive research in children on the responses to exercise in the heat. He also recognized and publicized the dangers posed by childhood obesity. With Heigenhaiser and Meyer, MacDougall and Heigenhauser, he applied the Stewart approach to the development of sweat production in male and female subjects (46).

Homeostasis in heavy exercise involves not only the handling of large amounts of lactate, but also shifts in other fully dissociated ions, as well as water among the muscle intracellular space, plasma and red blood cell. The previously held concepts of 'oxygen debt', 'anaerobic threshold' and 'lactic acidosis of exercise' have been replaced by the newer paradigms of caloric and ionic homeostasis.

\section{DYSPNEA}

Moran Campbell was the first person to rigorously study the sensations associated with breathing. In his book The Respiratory Muscles and the Mechanics of Breathing (47), published in 1958, he explored the action of respiratory muscles through electromyography and pressure measurements. With his colleague, Jack Howell, he studied the ability of people to detect applied loads to breathing. In the early 1960s, they interested a number of medical students in the problem. Together, they developed an experimental setup worthy of the eccentric cartoonist Heath Robinson. The 'loads' were generated by breathing from closed canisters leading to an 'elastic' load and through perforated tubes covered with porous paper, which provided 'resistive' loads (48). The canisters were of varying volumes, from the size of a bucket to several large oil drums connected together - the smaller the volume, the more pressure was required to obtain a breath; the resistive loads could be varied by changing the size of the tubes. The pressure required to breathe was measured at the mouth, and the loads were presented randomly, with the subject asked to indicate when a change in load was detected. This was a similar concept to the approach of 'just noticeable differences', introduced in 1814 by EH Weber and adopted by GT Fechner, the 'father of psychophysics'. Campbell and Howell (49) found that a change of approximately $20 \%$ was required over the natural load to breathing for the load to be detected. The stimulus for detection could not be explained by any change in lung volume, flow or pressure. Detection had to be related to the interaction between force and displacement. Because changes in lung volume were associated with changes in respiratory muscle length, and because changes in pressure reflected changes in muscle tension, they proposed the concept of 'length-tension inappropriateness' as the signal for the sensation of breathlessness. Moran Campbell carried a rubber band to illustrate the concept, which was analogous to judging the stiffness of the band: "To do this, one normally pulls the band in and out, noting the sensation. One neither fixes one end and observes the change in length for a given pull, nor the pull required to obtain a given length." On this relatively simple concept was built a complex neurophysiological edifice. The concept was later extended to include inappropriateness in several different guises, for example, when breathing was sensed to be inappropriate for a given activity.

On his arrival at McMaster University, Campbell made use of the architecturally driven strategy adopted for building the Medical Centre (only four stories high, but in a four-by-four section ground plan, each of the 16 sections being erected separately) to commandeer space for a laboratory. With Kieran Killian, he set about expanding his previous studies of loaded breathing. What was the mechanism responsible for resistive and elastic load detection? Campbell had a fascination for the muscle spindle, which he suspected played a unique role. Early studies proved disappointing. Killian et al (50) showed that resistive load detection occurred early in the breath, and could only be explained by a critical phase lag of $6^{\circ}$ in the rise of pressure relative to flow. The detection of loads and the distress of the experience may not be mediated by the same mechanism. Killian added resistive and elastic loads at different tidal volumes and flow rates. The perceived magnitude of the load appeared to be closely related to the peak force (51). Altose and Cherniack (52) came to the same conclusion with a different approach. Progress was rapid, and it became apparent that people can easily detect, recognize and discriminate several different sensations in the act of breathing. Volume, flow, pressure and the magnitude of resistive and elastic loads may all be independently perceived, given the right conditions (53).

Progressive loading of respiratory muscles is associated with increasing breathlessness to the limit of tolerance. Respiratory failure is induced with $\mathrm{CO}_{2}$ retention and arterial $\mathrm{O}_{2}$ desaturation. Jones et al (54) showed that when the respiratory muscles were progressively loaded to failure, distress increased with peak pressure but was systematically greater as the strength of respiratory muscles declined. David Stubbing had subjects generate pressures for various inspiratory durations and at different frequencies of breathing. Unique psychophysical functions emerged in which the magnitude of sensation was an interactive function of both duration and frequency. Subjects minimized distress by increasing either inspiratory duration or frequency (55). 
Pere Casan, visiting from Barcelona, Spain, compared progressive incremental loading with resistive, elastic and dead space loading to tolerance. At the limit, the work and energy costs of breathing differed widely between the conditions. Dyspnea was not uniquely related to the associated energy consumption (56).

The breakthrough in measurement of sensory intensity was provided by Stanley Smith Stevens, who over four decades in his laboratory at Harvard University (Massachusetts, USA), applied mathematical insight and rigorous experimental techniques to make modern psychophysics his own. His book Psychophysics. Introduction to its perceptual, neural, and social prospects (57) was published in 1975, two years after his death. In this book, he summarized the extensive evidence that led him to state a law that has similar attractions - rigour and simplicity - as the law developed by Weber and his colleague Fechner, ie, equal stimulus ratios produce equal sensation ratios. Steven's psychophysical law was a power function (In mathematical terms, the sensation magnitude $[\psi]$ is a power function of the stimulus magnitude $[\varphi]-\psi=\kappa\left(\varphi^{\beta}\right.$.) Mathematically, this meant that any sensation capable of being scaled could be expressed in terms of the stimulus intensity raised to an exponent (power) whose value was an attribute of the quality of the sensation. For example, the sense of effort experienced during a measured hand grip had a power of 1.7; for a doubling of the applied force, the sense of effort increased by two raised to the power 1.7 , or 3.2 times. In contrast, the perception of loudness has a power function exponent of 0.67 , so that a doubling of sound pressure was appreciated as a $1.6 \times 2^{0.67}$ increase in loudness.

The Swedish psychologist, Gunnar Borg, was a student of Stevens in the 1950s who applied his mentor's scaling techniques to quantify perceived effort during exercise. He showed that effort satisfied Stevens' power law; work intensity increased with an exponent of 1.6, ie, a doubling of work intensity increased effort by threefold. In the 1970s, he turned this finding into a scale of practical utility by fixing the two ends of the scale ( 0 to 10$)$ and linking the intervening numbers to verbal descriptions (such as "light", "moderate" and "somewhat hard"), which, through many studies, he showed had preserved the ratio qualities. He tested the scale in populations of varying educational levels and languages to test its general validity. The 'Borg scale' has proved to be a remarkably useful tool for assessing symptom intensity, particularly during progressive exercise, in which symptoms may increase from zero to intolerable (58).

The usefulness of the Borg scale in quantifying the sense of effort in breathing and dyspnea lay in the fact that it could be used as a dependent variable, allowing the recognition of its independent contributors in a quantitative framework. El-Manshawi et al (59) combined exercise and external loading of respiratory muscles, quantifying dyspnea with the Borg scale. The most important factor contributing to the effort of breathing was the pressure (tension) achieved by the respiratory muscles, expressed as a fraction of the muscle strength (maximum inspiratory pressure). Differences between individuals' perceptions are often related to differences in strength. Perhaps it should not have come as a surprise that maximum inspiratory pressure was largely variable, from $50 \mathrm{~cm} \mathrm{H}_{2} \mathrm{O}$ to $250 \mathrm{~cm} \mathrm{H} \mathrm{H}_{2} \mathrm{O}-\mathrm{a}$ fivefold range. Other factors included the total ventilation, the size of each breath, the frequency of breathing and the rapidity of inspiration. Increased loads to breathing acted through the increases in pressure required to breathe against them (59). The sensation of effort in breathing was found to be closely similar to the sense of effort experienced in any other muscular task, which depends on the load (tension) as a proportion of the muscle strength, the extent of the muscle contraction (size of breath), the frequency of contraction and the velocity of contraction (speed of inspiration or flow). LeBlanc et al (60) showed that the sense of effort increased in patients during exercise, with increases in esophageal pressure, as well as in length and velocity of inspiratory muscle contraction. He went on to report that the effect of lung volume (representing length of inspiratory muscles) and inspiratory flow (representing velocity of contraction) depended on the capacity to generate pressure (61). He also showed that breathing is initiated at high lung volume because the respiratory muscles start from a shortened position - analogous to trying to lift a weight with your elbow already bent. Stubbing et al (62) studied normal subjects and patients with COPD as they exercised in a body plethysmograph. The COPD patients adapted to airflow limitation by increasing end-expiratory volume (later termed dynamic hyperinflation), thereby progressively shortening the inspiratory muscles and losing the normal unloading that accompanies the reduction in end-expiratory volume to below the resting functional residual capacity (63).

For 200 years, there was an implicit acceptance that chemoreceptor stimulation was accompanied by breathlessness. In 1966, Campbell et al (64) decided that the only way to discover whether dyspnea was instead sensed through receptors in the respiratory muscles, signalling tension to the brain, was to eliminate muscle tension with curare. He was the first of two subjects. A blood pressure cuff prevented paralysis of the hand, so that Campbell could signal with his thumb in response to regular questions. During the study, he tolerated a 4 min-long suspension of his breathing, during which the $\mathrm{CO}_{2}$ pressure increased from $36 \mathrm{mmHg}$ to $60 \mathrm{mmHg}$ - a level that is usually intolerable - without feeling any distress or 'drive' to breathe. It was also certainly less than the distress of the team looking after the study, as we collectively 'held our breath' until it was all safely over. A second subject, Mark Noble, underwent the procedure with similar results. This seemed to 'prove' that the drive to breathe, at least during a breathhold, was mainly an impression of an intolerable tension in respiratory muscles prevented from contracting (64). However, Banzett et al (65), at Harvard University, also underwent curarization supported by mechanical ventilation. The addition of $\mathrm{CO}_{2}$ to inspired gas rapidly led to breathlessness. Gandevia et al (66) confirmed their findings, with Killian as a subject, concluding that "dyspnea is preserved following neuromuscular blockade". This suggested that chemoreceptor activity, via the central neuronal activity which it evokes, can lead to breathlessness in the absence of any contraction of respiratory muscles. Breathlessness and dyspnea are due to different mechanisms. Arguments will inevitably continue, because chemoreceptor activity leads to respiratory muscle drive. Gandevia (67) showed that stimuli arising in the higher brain, whether to initiate a movement voluntarily or as part of a reflex, are sensed through what is termed "corollary discharge".

In the cardiorespiratory unit at McMaster University, one of our main aims during the 1970s was to develop an exercise testing system that could be used in all situations, including healthy adults and children, as well as patients with cardiac, 
respiratory and neurological disorders. Simple, noninvasive measurements were made during exercise on a cycle ergometer, which progressed in steps from rest to a symptom-limited maximum in $10 \mathrm{~min}$ to $20 \mathrm{~min}$. Limiting symptoms in a test of this sort usually consist of severe leg muscle fatigue, shortness of breath and chest pain. All these symptoms can be quantified with the Borg scale and examined in relation to such responses as heart rate, and blood pressure, electrocardiogram and respiratory measurements. The database grew to exceed 40,000 studies, and allowed us to generalize the main factors that limit exercise. Kieran Killian made imaginative use of the data to help tease out these factors and assess their contribution to an individual's disability. Breathlessness, then, can be seen to result from an imbalance between the demand for breathing and the ability to achieve the demand in the face of the respiratory system's impedances (resistive and elastic).

The Borg scale has been especially useful in assessing the factors contributing to limiting symptoms in exercise. Kearon et al (68) showed that in normal subjects during endurance, as well as progressive incremental exercise, dyspnea increased as power functions of both duration and intensity. Leg muscle effort similarly increases in healthy subjects (69). In COPD patients, the intensity of leg muscle effort increases as leg muscle strength declines (70). Maltais et al (71) at Laval University (Quebec City, Quebec) showed that reductions in exercise capacity in patients with COPD were associated with excess lactate production; disabled COPD patients showed changes in muscle enzyme activity that suggested a metabolic myopathy. Lands et al $(72,73)$ conducted a series of studies to define factors limiting exercise in cystic fibrosis. They found that reductions in muscle strength paralleled lean body mass (72), and that respiratory impairment and weak skeletal muscles were major limiting factors, with cardiac output and respiratory muscle strength being normal (73). In doing so, he dissected the contribution of central and peripheral (muscle) impairment to reductions in exercise capacity in the condition.

The demand for breathing is primarily metabolic, related to $\mathrm{CO}_{2}$ production, and secondarily reflex, related to stimuli arising in receptors that respond to increased $\mathrm{CO}_{2}$, increased acidity (hydrogen ion concentration) and reduced blood $\mathrm{O}_{2}$

\section{REFERENCES}

1. Barcroft J. Features in the Architecture of Physiological Function. Cambridge: Cambridge University Press, 1934.

2. Jones NL, Robertson DG, Kane JW, Campbell EJ. Effect of $\mathrm{P} \mathrm{CO}_{2}$ level on alveolar-arterial $\mathrm{P} \mathrm{CO}_{2}$ difference during rebreathing. J Appl Physiol 1972;32:782-7.

3. Alves da Silva G, el-Manshawi A, Heigenhauser GJ, Jones NL. Measurement of mixed venous carbon dioxide pressure by rebreathing during exercise. Respir Physiol 1985;59:379-92.

4. Jones NL, Robertson DG, Kane JW. Difference between end-tidal and arterial $\mathrm{PCO}_{2}$ in exercise. J Appl Physiol 1979;47:954-60.

5. McKelvie RS, Heigenhauser GJ, Jones NL. Measurement of cardiac output by $\mathrm{CO}_{2}$ rebreathing in unsteady state exercise. Chest 1987;92:777-82.

6. Jones NL, Makrides L, Hitchcock C, Chypchar T, McCartney N. Normal standards for an incremental progressive cycle ergometer test. Am Rev Respir Dis 1985;131:700-8.

7. McCartney N, Heigenhauser GJ, Sargeant AJ, Jones NL. A constant-velocity cycle ergometer for the study of dynamic muscle function. J Appl Physiol 1983;55:212-7.

8. McCartney N, Obminski G, Heigenhauser GJ. Torque-velocity relationship in isokinetic cycling exercise. J Appl Physiol 1985;58:1459-62. saturation, and to stimuli in higher brain centres. The ability to achieve the demand in comfort is reduced by increases in lung stiffness (elastic recoil) and resistance to airflow (airway narrowing), as well as by weakness of the respiratory muscles. In addition to reduced strength of the muscles, they are weakened when required to work at a shortened length (ie, at high lung volume), high velocity (shortened time for inspiration), high frequency and long duration. The quantitative interaction between these factors was demonstrated by Pierre Leblanc, Denis Bowie and colleagues (74) in patients with a variety of cardiorespiratory disorders.

Clarification of the factors that contribute to dyspnea and leg muscle effort came from the application of psychophysical principles to the scaling of the sensations that progressively increase with exercise, which were then related to indirect measures of muscle strength and function.

\section{CONCLUSIONS}

At McMaster University, several parallel research paths were followed that complemented each other to increase understanding of exercise in health and disease (75). Muscle strength, metabolic function and ionic homeostasis are preeminent factors determining the capacity to exercise. This applies both to health and to situations in which $\mathrm{O}_{2}$ delivery is compromised. These factors also contribute to limiting symptoms. Symptom intensity can be reliably scaled during standardized incremental exercise testing and interpreted in the light of physiological measurements. The classical concepts of $\mathrm{O}_{2}$ debt and the anaerobic threshold have been replaced. The effects of training on performance are mediated by improvements in strength, metabolic control and ionic homeostasis, rather than through central $\mathrm{O}_{2}$ delivery.

ACKNOWLEDGEMENTS: I am grateful to Kieran Killian and George Heigenhauser for their extensive and constructive comments. We have been supported by the Canadian Institutes for Health Research and the Ontario Heart Foundation. We remain indebted to colleagues at McMaster University and elsewhere who have collaborated with us to make our joint research greater than the sum of its parts. Above all, it has been our good fortune to work with four stars - Moran Campbell, Eric Hultman, Eric Newsholme and Peter Stewart.

9. Jones NL, McCartney N, Graham T, et al. Muscle performance and metabolism in maximal isokinetic cycling at slow and fast speeds. J Appl Physiol 1985;59:132-6.

10. McCartney N, Spriet LL, Heigenhauser GJ, Kowalchuk JM, Sutton JR, Jones NL. Muscle power and metabolism in maximal intermittent exercise. J Appl Physiol 1986;60:1164-9.

11. Makrides L, Heigenhauser GJ, McCartney N, Jones NL. Maximal short term exercise capacity in healthy subjects aged $15-70$ years. Clin Sci (Lond) 1985;69:197-205.

12. Makrides L, Heigenhauser GJ, Jones NL. High-intensity endurance training in 20- to 30 - and 60- to 70-yr-old healthy men. J Appl Physiol 1990;69:1792-8.

13. Simpson K, Killian K, McCartney N, Stubbing DG, Jones NL. Randomized controlled trial of weightlifting exercise in patients with chronic airflow limitation. Thorax 1992;47:70-5.

14. Jones NL, Summers E, Killian KJ. Influence of age and stature on exercise capacity during incremental cycle ergometry in men and women. Am Rev Respir Dis 1989;140:1373-80.

15. Jones NL. Clinical Exercise Testing, 4th edn. Philadelphia: WB Saunders, 1997. 
16. Guyatt GH, Sullivan MJ, Thompson PJ, et al. The 6-minute walk: A new measure of exercise capacity in patients with chronic heart failure. Can Med Assoc J 1985;132:919-23.

17. Harris P. Lactic acid and the phlogiston debt. Cardiovasc Res 1969;3:381-90.

18. Jones NL, Sutton JR, Taylor R, Toews CJ. Effect of $\mathrm{pH}$ on cardiorespiratory and metabolic responses to exercise. J Appl Physiol 1977;43:959-64.

19. Spriet LL, Lindinger MI, Heigenhauser GJ, Jones NL. Effects of alkalosis on skeletal muscle metabolism and performance during exercise. Am J Physiol 1986;251:R833-9.

20. Spriet LL, Heigenhauser GJ, Jones NL. Endogenous triacylglycerol utilization by rat skeletal muscle during tetanic stimulation. J Appl Physiol 1986;60:410-5.

21. McCartney N, Heigenhauser GJ, Jones NL. Effects of $\mathrm{pH}$ on maximal power output and fatigue during short-term dynamic exercise. J Appl Physiol 1983;55:225-9.

22. Jones NL, Robertson DG, Kane JW, Hart RA. Effect of hypoxia on free fatty acid metabolism during exercise. J Appl Physiol 1972;33:733-8.

23. Sutton JR, Reeves JT, Wagner PD, et al. Operation Everest II: Oxygen transport during exercise at extreme simulated altitude. J Appl Physiol 1988;64:1309-21.

24. Sutton JR, Jones NL, Toews CJ. Effect of $\mathrm{pH}$ on muscle glycolysis during exercise. Clin Sci (Lond) 1981;61:331-8.

25. Bonen A, McCullagh KJ, Putman CT, Hultman E, Jones NL, Heigenhauser GJ. Short-term training increases human muscle MCT1 and femoral venous lactate in relation to muscle lactate. Am J Physiol 1998;274:E102-7.

26. Newsholme EA, Start C. Regulation in Metabolism. London: John Wiley and Sons, 1973.

27. Ward GR, Sutton JR, Jones NL, Toews CJ. Activation by exercise of human skeletal muscle pyruvate dehydrogenase in vivo. Clin Sci (Lond) 1982;63:87-92.

28. Ward GR, MacDougall JD, Sutton JR, Toews CJ, Jones NL. Activaton of human muscle pyruvate dehydrogenase with activity and immobilization. Clin Sci (Lond) 1986;70:207-10.

29. Putman CT, Jones NL, Lands LC, Bragg TM, Hollidge-Horvat MG, Heigenhauser GJ. Skeletal muscle pyruvate dehydrogenase activity during maximal exercise in humans. Am J Physiol 1995;269:E458-68.

30. Putman CT, Spriet LL, Hultman E, et al. Pyruvate dehydrogenase activity and acetyl group accumulation during exercise after different diets. Am J Physiol 1993;265:E752-60.

31. Putman CT, Jones NL, Hultman E, et al. Effects of short-term submaximal training in humans on muscle metabolism in exercise. Am J Physiol 1998;275:E132-9.

32. Hollidge-Horvat MG, Parolin ML, Wong D, Jones NL, Heigenhauser GJ. Effect of induced metabolic acidosis on human skeletal muscle metabolism during exercise. Am J Physiol 1999;277:E647-58

33. Parolin ML, Spriet LL, Hultman E, Hollidge-Horvat MG, Jones NL, Heigenhauser GJ. Regulation of glycogen phosphorylase and PDH during exercise in human skeletal muscle during hypoxia. Am J Physiol 2000;278:E522-34.

34. Parolin ML, Spriet LL, Hultman E, et al. Effects of PDH activation by dichloroacetate in human skeletal muscle during exercise in hypoxia. Am J Physiol Endocrinol Metab 2000;279:E752-61.

35. Spriet LL, Heigenhauser GJ. Regulation of pyruvate dehydrogenase $(\mathrm{PDH})$ activity in human skeletal muscle during exercise. Exerc Sport Sci Rev 2002;30:91-5.

36. Taylor R, Jones NL. The reduction by training of $\mathrm{CO}_{2}$ output during exercise. Eur J Cardiol 1979;9:53-62.

37. Spriet LL, Matsos CG, Peters SJ, Heigenhauser GJ, Jones NL. Muscle metabolism and performance in perfused rat hindquarter during heavy exercise. Am J Physiol 1985;248:C109-18.

38. Spriet LL, Matsos CG, Peters SJ, Heigenhauser GJ, Jones NL. Effects of acidosis on rat muscle metabolism and performance during heavy exercise. Am J Physiol 1985;248:C337-47.

39. Stewart PA. Modern quantitative acid-base chemistry. Can J Physiol Pharmacol 1983;61:1444-61.

40. Lindinger MI, Heigenhauser GJ. Intracellular ion content of skeletal muscle measured by instrumental neutron activation analysis. J Appl Physiol 1987;63:426-33.

41. Kowalchuk JM, Heigenhauser GJF, Lindinger MI, Sutton JR, Jones NL. Factors influencing hydrogen ion concentration in muscle after intense exercise. J Appl Physiol 1988;65:2080-9.
42. Kowalchuk JM, Heigenhauser GJ, Lindinger MI, Obminski G, Sutton JR, Jones NL. Role of lungs and inactive muscle in acid-base control after maximal exercise. J Appl Physiol 1988;65:2090-6.

43. McKelvie RS, Lindinger MI, Heigenhauser GJ, Jones NL. Contribution of erythrocytes to the control of the electrolyte changes of exercise. Can J Physiol Pharmacol 1991;69:984-93.

44. Putman CT, Jones NL, Heigenhauser GJ. Effects of short-term training on plasma acid-base balance during incremental exercise in man. J Physiol 2003;550:585-603.

45. Mckenna MJ, Heigenhauser GJ, McKelvie RS, MacDougall JD, Jones NL. Sprint training enhances ionic regulation during intense exercise in men. J Physiol 1997;501:687-702.

46. Meyer F, Bar-Or O, MacDougall D, Heigenhauser GJ. Sweat electrolyte loss during exercise in the heat: Effects of gender and maturation. Med Sci Sports Exerc 1992;24:776-81.

47. Campbell EJM. The Respiratory Muscles and the Mechanics of Breathing. London: Lloyd-Luke, 1958.

48. Bennett ED, Jayson MI, Rubenstein D, Campbell EJ. The ability of man to detect added non-elastic loads to breathing. Clin Sci 1962;23:155-62.

49. Campbell EJ, Howell JB. The sensation of breathlessness. Br Med Bull 1963;19:36-40.

50. Killian KJ, Mahutte CK, Howell JB, Campbell EJ. Effect of timing, flow, lung volume and threshold pressures on resistive load detection. J Appl Physiol 1980;49:958-63.

51. Killian KJ, Mahutte CK, Campbell EJM. Magnitude scaling of externally added loads to breathing. Am Rev Respir Dis 1981;123:12-5

52. Altose MD, Cherniack NS. Respiratory sensation and respiratory muscle activity. Adv Physiol Sci 1981;10:111-9.

53. Killian KJ, Campbell EJM. Dyspnea. In: Roussos C, Macklem PT, eds. The Thorax, Part B. New York: Marcel Dekker, 1985:787-828.

54. Jones GL, Killian KJ, Summers E. The sense of effort, oxygen cost, and pattern of breathing associated with progressive elastic loading to fatigue. Fed Proc 1984;42:1420. (Abst)

55. Stubbing DG, Killian KJ, Campbell EJ. The quantification of respiratory sensations by normal subjects. Respir Physiol 1981;44:251-60.

56. Casan P, Villafranca CC, Kearon MC, Campbell EJ, Killian KJ. Contribution of respiratory muscle oxygen consumption to breathing limitation and dyspnea. Can Respir J 1997;4:101-7.

57. Stevens SS. Psychophysics. Introduction to its Perceptual, Neural, and Social Prospects. New York: John Wiley and Sons, 1975.

58. Borg G, Ljunggren G, Ceci R. The increase of perceived exertion, aches and pain in the legs, heart rate and blood lactate during exercise on a bicycle ergometer. Eur J Appl Physiol 1989;54:343-9.

59. el-Manshawi A, Killian KJ, Summers E, Jones NL. Breathlessness during exercise with and without resistive loading. J Appl Physiol 1986;61:896-905.

60. Leblanc P, Bowie DM, Summers E, Jones NL, Killian KJ Breathlessness and exercise in patients with cardiorespiratory disease. Am Rev Respir Dis 1986;133:21-5.

61. Leblanc P, Summers E, Inman MD, Jones NL, Campbell EJ, Killian KJ. Inspiratory muscles during exercise: A problem of supply and demand. J Appl Physiol 1988;64:2482-9.

62. Stubbing DG, Pengelly LD, Morse JL, Jones NL. Pulmonary mechanics during exercise in normal males. J Appl Physiol 1980;49:506-10.

63. Stubbing DG, Pengelly LD, Morse JL, Jones NL. Pulmonary mechanics during exercise in subjects with chronic airflow obstruction. J Appl Physiol 1980;49:511-5.

64. Campbell EJ, Freedman S, Clark TJ, Robson JG, Norman J. The effect of muscular paralysis induced by tubocurarine on the duration and sensation of breath-holding. Clin Sci 1967;32:425-32.

65. Banzett RB, Lansing RW, Brown R, et al. 'Air hunger' from increased $\mathrm{PCO}_{2}$ persists after complete neuromuscular block in humans. Respir Physiol 1990;81:1-17.

66. Gandevia SC, Killian K, McKenzie DK, et al. Respiratory sensations, cardiovascular control, kinaesthesia and transcranial stimulation during paralysis in humans. J Physiol 1993:470:85-107.

67. Gandevia SC. Neural mechanisms underlying the sensation of breathlessness: Kinesthetic parallels between respiratory and limb muscles. Aust N Z J Med 1988;18:83-91. 
68. Kearon MC, Summers E, Jones NL, Campbell EJ, Killian KJ. Effort and dyspnoea during work of varying intensity and duration. Eur Respir J 1991;4:917-25.

69. Hamilton AL, Killian KJ, Summers E, Jones NL. Quantification of intensity of sensations during muscular work by normal subjects. J Appl Physiol 1996;81:1156-61.

70. Jones NL, Killian KJ. Limitation of exercise in chronic airway obstruction. In: Cherniack NS, ed. Chronic Obstructive Pulmonary Disease. Philadelphia: WB Saunders Co, 1991:196-206.

71. Maltais F, Jobin J, Sullivan MJ, et al. Metabolic and hemodynamic responses of lower limb during exercise in patients with COPD. J Appl Physiol 1998;84:1573-80.
72. Lands LC, Heigenhauser GJ, Jones NL. Analysis of factors limiting maximal exercise performance in cystic fibrosis. Clin Sci (Lond) 1992;83:391-7.

73. Lands LC, Heigenhauser GJ, Jones NL. Respiratory and peripheral muscle function in cystic fibrosis. Am Rev Respir Dis 1993; 147:865-9.

74. Leblanc P, Bowie DM, Summers E, Jones NL, Killian KJ. Breathlessness and exercise in patients with cardiorespiratory disease. Am Rev Respir Dis 1986;133:21-5.

75. Jones NL, Killian KJ. Exercise limitation in health and disease. N Engl J Med 2000;343:632-41. 


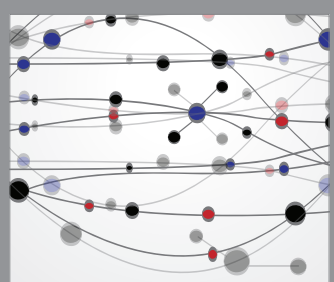

The Scientific World Journal
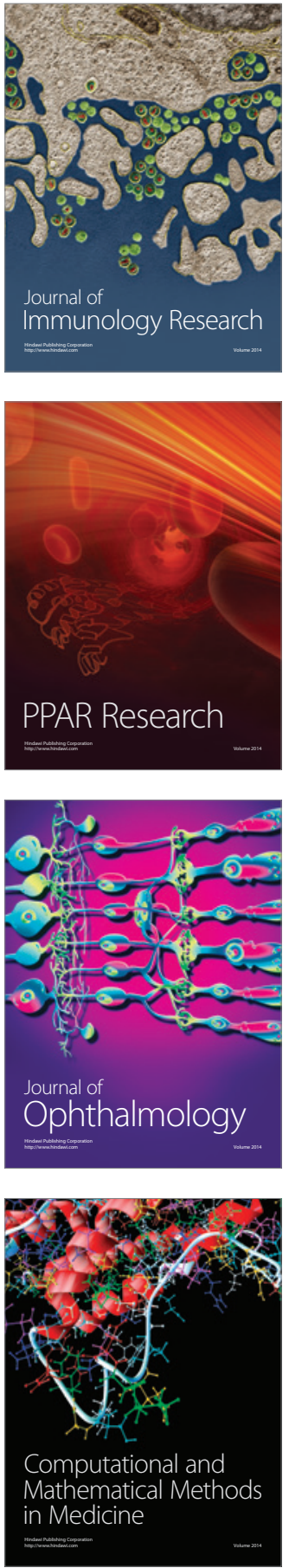

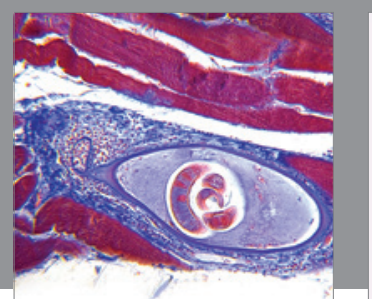

Gastroenterology Research and Practice

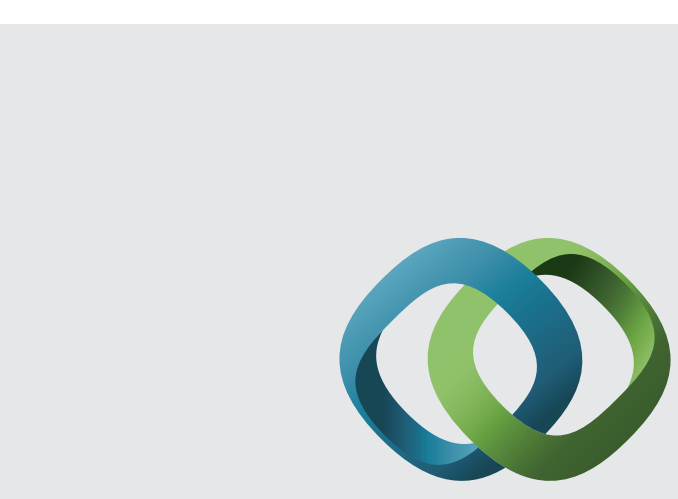

\section{Hindawi}

Submit your manuscripts at

http://www.hindawi.com
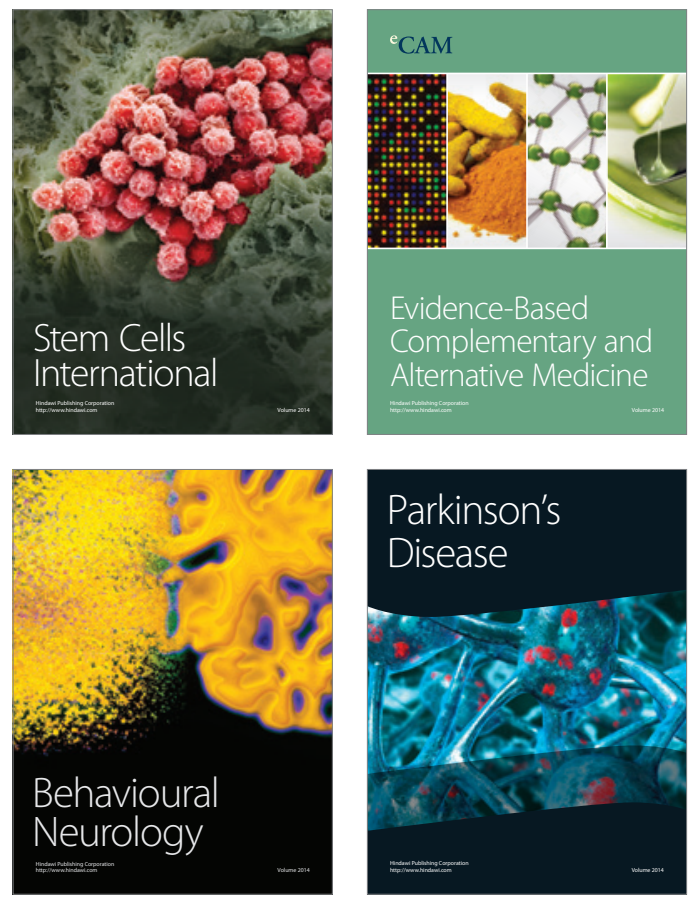
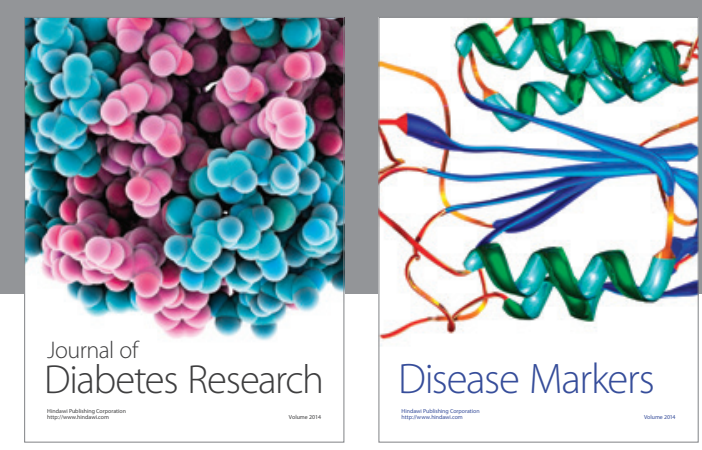

Disease Markers
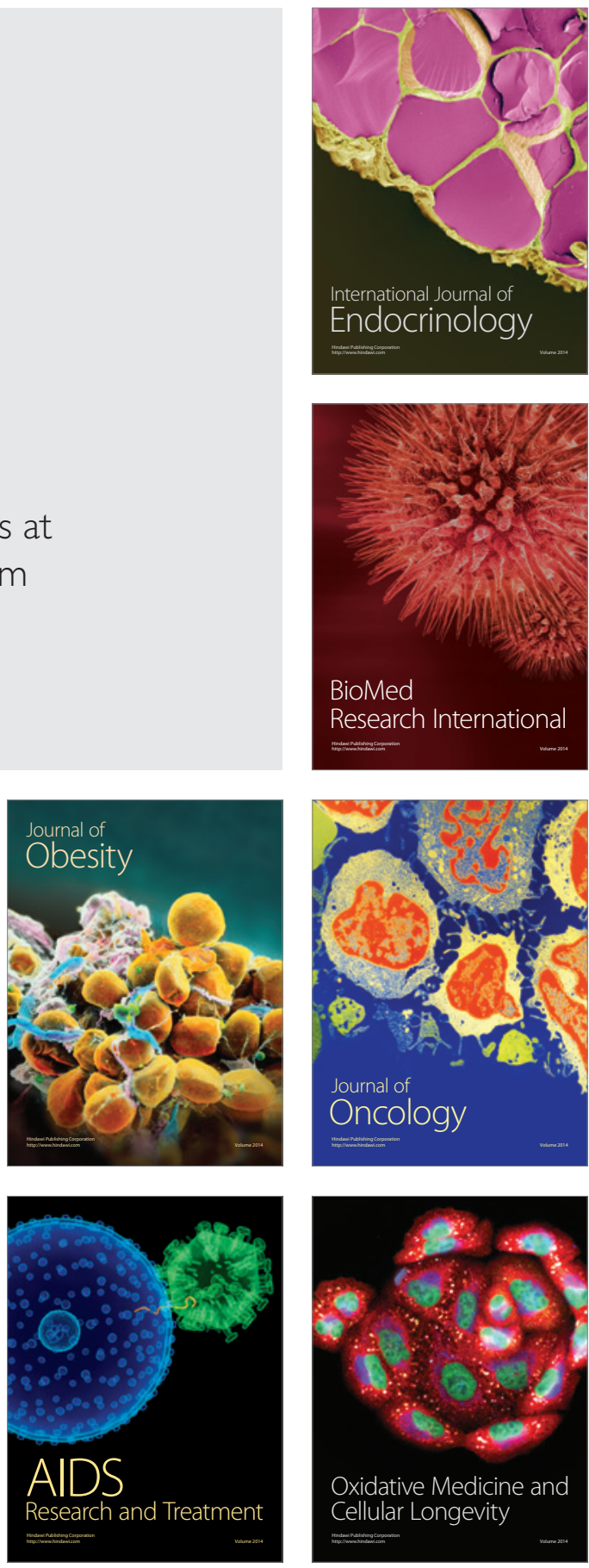